\title{
1 \\ Launching the Century of the Patient
}

\author{
Gerd Gigerenzer and J. A. Muir Gray
}

\begin{abstract}
Efficient health care requires informed doctors and patients. The health care system inherited from the 20th century falls short on both counts. Many doctors and most patients do not understand the available medical evidence. Seven "sins" are identified which have contributed to this lack of knowledge: biased funding; biased reporting in medical journals; biased patient pamphlets; biased reporting in the media; conflicts of interest; defensive medicine; and medical curricula that fail to teach doctors how to comprehend health statistics. These flaws have generated a partially inefficient system that wastes taxpayers' money on unnecessary or even potentially harmful tests and treatments as well as on medical research that is of limited relevance to the patient. Raising taxes or rationing care is often seen as the only viable alternative to exploding health care costs. Yet there is a third option: by promoting health literacy, better care is possible for less money. The 21 st century should become the century of the patient. Governments and health institutions need to change course and provide honest and transparent information to enable better doctors, better patients, and, ultimately, better health care.
\end{abstract}

\section{Introduction}

Patients appear to be the problem in modern high-tech health care: they are uninformed, anxious, noncompliant folk with unhealthy lifestyles. They demand drugs advertised by celebrities on television, insist on unnecessary but expensive computer tomography (CT) and magnetic resonance imaging (MRI) scans, and may eventually turn into plaintiffs. Patients' lack of health literacy and the resulting costs and harms have received much attention. Consider the following cases.

Almost ten million U.S. women have had unnecessary Pap smears to screen for cervical cancer - unnecessary because, having already undergone complete hysterectomies, these women no longer had a cervix (Sirovich and Welch 2004). Unnecessary Pap tests cause no harm to the patient, but in terms of the 
health system, they waste millions of dollars which could have been used elsewhere to better health care.

Every year, one million U.S. children have unnecessary CT scans (Brenner and Hall 2007). An unnecessary CT scan equates to more than a waste of money: an estimated 29,000 cancers result from the approximately 70 million CT scans performed annually in the United States (González et al. 2009); people who have a full-body CT scan can be exposed to radiation levels comparable to some of the atomic-bomb survivors from Hiroshima and Nagasaki (Brenner and Hall 2007). Why don't parents protect their children from unnecessary doses of radiation? They probably would if only they knew. When a random sample of 500 Americans was asked whether they would rather receive one thousand dollars in cash or a free full-body CT, 3 out of 4 wanted the CT (Schwartz et al. 2004).

The uninformed patient is not restricted to the United States. A representative study of 10,228 people from nine European countries revealed that $89 \%$ of men and $92 \%$ of women overestimated the benefit of PSA and mammography screening tenfold, hundredfold and more, or did not know (Gigerenzer et al. 2007). Why don't people know, or want to know?

Answers that have been proposed range from the perception that patients are not intelligent enough to they just do not want to see numbers, even though most American 12-year-olds already know baseball statistics and their British peers can easily recite the relevant numbers of the Football Association Cup results. Scores of health psychologists and behavioral economists add to the list of suspected cognitive deficits by emphasizing patients' cognitive biases, weakness of will, and wishful thinking. In this view, the problems in health care stem from people who engage in self-harming behavior, focus on shortterm gratification rather than long-term harms, suffer from the inability to make forecasts of their emotional states after a treatment, or simply do not want to think but prefer to trust their doctor. The recommended remedies are consequently some form of paternalism that "nudges" the immature patient in the right direction (Thaler and Sunstein 2008). The 20th century has focused the spotlight on the patient who lacks health literacy.

We take a different position. Today's problem is less the patient than the health system we inherited. The patient is only the last element in a chain that actively creates and sustains health illiteracy. In this chapter, we identify seven "sins" of the 20th-century health care system and advocate a change toward a 21 st-century system centered around patients - not industries, organizations, or doctors.

Raising taxes or rationing care is often viewed as the only alternative to exploding health care costs. We argue that there is a third option: by promoting health literacy, we can get better care for less money. However, what is ultimately at stake is more than just health and money: an educated citizenry is the lifeblood of a modern democracy. We begin with an example that demonstrates 
how difficult it can be for a patient to make sense out of the barrage of misinformation, so as to be able to make an informed decision.

\section{Misinformed Men: John Q. Public and Otto Normalverbraucher}

In his early fifties, John Q. Public intends to make an informed decision about whether to participate in prostate cancer screening with PSA tests. He lives in New York and recalls what Rudi Giuliani, former mayor of New York City, said in a 2007 campaign advertisement (Dobbs 2007):

I had prostate cancer, 5, 6 years ago. My chance of surviving prostate cancerand thank God, I was cured of it-in the United States? Eighty-two percent. My chance of surviving prostate cancer in England? Only 44 percent under socialized medicine.

John concludes that he is lucky to live in New York rather than York. He also recalls that back in the late 1990s, Congress initiated a postal stamp featuring "Prostate Cancer Awareness," which promoted "annual checkups and tests." Giuliani and the U.S. Postal Service were obviously of one mind. Yet John looks for further information. He reads that US\$3 billion is spent every year on PSA tests and follow-ups, and that the majority of primary care physicians perform routine PSA testing, even in men over 80 years of age. What finally convinces him is that $95 \%$ of male urologists and $78 \%$ of primary care physicians 50 years and older report that they have undergone PSA screening themselves (Barry 2009). He believes he has enough information and decides that he will take PSA tests because they save lives and lead to little or no harm. Has John Q. Public made an informed decision?

No, but he will likely never know. For one, he may not realize that he was misled by Rudi Giuliani, who presented high 5-year survival rates as suggestive evidence for lower mortality, when in fact differences in survival rates are uncorrelated with differences in mortality rates (Welch et al. 2000). In reality, mortality from prostate cancer is about the same in the United States and the United Kingdom, even though most American men take the PSA test and most British men do not. There are two reasons why high survival rates tell us nothing about lower mortality in the context of screening: Screening results in early detection and thus increases 5-year survival rates by setting the time of diagnosis earlier (lead-time bias). In addition, it also increases survival rates by including people with non-progressive cancers, which by definition do not lead to mortality (overdiagnosis bias; Gigerenzer et al. 2007). Giuliani is not the only one to have misled the public with survival rates; prestigious U.S. cancer centers such as MD Anderson at The University of Texas have done this as well (Gigerenzer et al. 2007). But surely, one might think, John's doctor would provide him with the truth. This, too, is unlikely, because very few doctors know that in screening, survival rates reveal nothing about mortality, 
just as many do not understand what lead-time bias and overdiagnosis bias are (Wegwarth, Gaissmaier, and Gigerenzer, submitted). This lack of statistical literacy in health may explain why so many urologists themselves take the test. John Q. Public is also unlikely to learn that a U.S. randomized trial found no reduction of prostate cancer deaths from combined screening with PSA and digital rectal examination (Andriole et al. 2009), but that one- to two-thirds of men could expect harms such as incontinence and impotence from surgery or radiation.

The American market-driven health care system has no monopoly on producing misinformed patients. In Germany, John Q. Public is known as Otto Normalverbraucher. Otto wants to make an informed decision, too, and-in keeping with the fact that Germans read more health pamphlets than any other European (Gigerenzer et al. 2009) — opens the 114-page pamphlet on prostate cancer published by the Deutsche Krebshilfe (2009), a highly respected nonprofit cancer care organization that receives large amounts of donations from the public. Otto reads that, according to experts, PSA tests are an important method for early detection, and that 10-year survival rates are higher than 80\% (Deutsche Krebshilfe 2009:15). He also consults a press release about a recent European randomized trial on prostate cancer screening, which states that PSA screening reduced mortality from prostate cancer by $20 \%$ - not as exciting as $80 \%$, but impressive all the same. In the news, Otto reads the unequivocal statement from the president of the German Urology Society: "The study shows without doubt that PSA testing saves lives" (The Epoch Times, 26 April 2009). The president is joined by German sport celebrities who recount their personal stories about how early detection saved their lives on TV talk shows and remind Otto to take responsibility for his health - without delay. Just to be sure, Otto consults his urologist, who recommends screening as well. Everything falls into place and he follows suit. Has Otto Normalverbraucher made an informed decision?

No. However, just like John, he will probably never notice. To begin, he may not learn that he has been misled by the $20 \%$ figure. What it refers to is a reduction from 3.7 to 3.0 in every 1,000 men who participate in screening, which is an absolute reduction of 0.7 in 1,000 , as reported in the original study (Schröder et al. 2009). Framing benefits in terms of relative risks (20\%) is a common way to mislead the public without actually lying. Second, Otto may not know the subtle distinction between reduced cancer mortality and reduced prostate cancer mortality (multiple cancers exist, which can make it difficult to make correct attributions). The European randomized trial did not report on total cancer mortality, but the U.S. trial did and found no difference in cancer mortality: in the screening group, 23.9 out of 1,000 men died of cancer, compared to 23.8 in the control group. This information is virtually never mentioned in health brochures, which seem more intent on increasing attendance rates than on informing patients. Finally, chances are slim that his urologist knows the scientific evidence and is able to explain to him the pros and cons 
of PSA screening. Out of a random sample of 20 Berlin urologists, only 2 knew the benefits and harms of PSA screening (Stiftung Warentest 2004). Even when physicians know the evidence, they may practice defensive medicine out of fear of litigation and recommend the test. For instance, only about half of 250 Swiss internists believed that the advantages of regular PSA screening outweigh its harms in men older than 50 years of age, but $75 \%$ recommended regular PSA screening to their patients. More than $40 \%$ of physicians recommended screening for legal reasons - to protect themselves against potential lawsuits (Steurer et al. 2009).

The scenarios of John Q. Public and Otto Normalverbraucher illustrate some of the ways in which the patient is misled by the health system inherited from the 20th century. In the following sections, we will explain these in more detail. The deluded patient is the victim of a chain of biased information. Such a health care system wastes taxpayers' money, physicians' time, and causes potential harm to patients' health. The main problem is not the patient, but the health care system itself.

\section{The 20th-Century Medical System Produces Health Illiteracy}

Why are patients and doctors misinformed about available evidence concerning standard tests and treatments? The problem begins even before medical research starts - with the funding of research. It continues with biased (incomplete or nontransparent) reporting of the results in medical journals and health brochures, and ends with innumerate physicians who misunderstand health statistics. Throughout, seven elements contribute to misinform patients and prevent them from noticing the facts (Table 1.1). It is not an exhaustive list, but constitutes what we believe are some of the most important sources of distortion and confusion.

There are additional factors outside the health care system which cannot be addressed here, such as the remarkably slow pace of educational systems to adjust their curricula to the 21 st century so as to include statistical literacy as

Table 1.1 Important sources that contribute to the health illiteracy of patients.

\begin{aligned} & \hline Biased funding of research \\ &+ Biased reporting in medical journals \\ &+ Biased reporting in health pamphlets \\ &+ Biased reporting in the media \\ &+ Commercial conflicts of interest \\ &+ Defensive medicine \\ &+ Doctors' lack of understanding of health statistics \\ & \hline$=$ Misinformed patients \\ & \hline\end{aligned}


a central topic, and the resulting blind spot in teaching health and financial literacy (Gigerenzer et al. 2007). We would like to emphasize that in pointing out the flaws of the 20th-century health system, our aim is not to criticize particular doctors, politicians, or industries but to analyze a system whose primary goal has not always been to provide the best outcome for the patient. Knowledge of the system is essential if we are to change it into a more efficient one that serves the patient.

However, before we continue, let us clarify terms. We use the terms "health literacy" and "statistical literacy" as two overlapping bodies of knowledge, whose intersection is "statistical literacy in health" (Figure 1.1). Statistical literacy in health does not require a degree in statistics. Rather, it means that patients and health care providers have basic competencies in understanding evidence and, most importantly, know which questions to ask. Health literacy, in turn, intersects with "health system literacy" (a basic understanding of how the health system works). For further information, see Gigerenzer et al. (2007) for a detailed definition of "minimal statistical literacy in health" and Bachmann et al. (2007), who have designed a short test for minimum health literacy.

The term "century of the patient" refers to a society where greater investments in health do not mean more profit for the industry, but rather more knowledge for doctors and patients. In fact, shortage of money (e.g., due to the recent financial crises) can be an enabler for the revolution we envision.

\section{Health literacy}

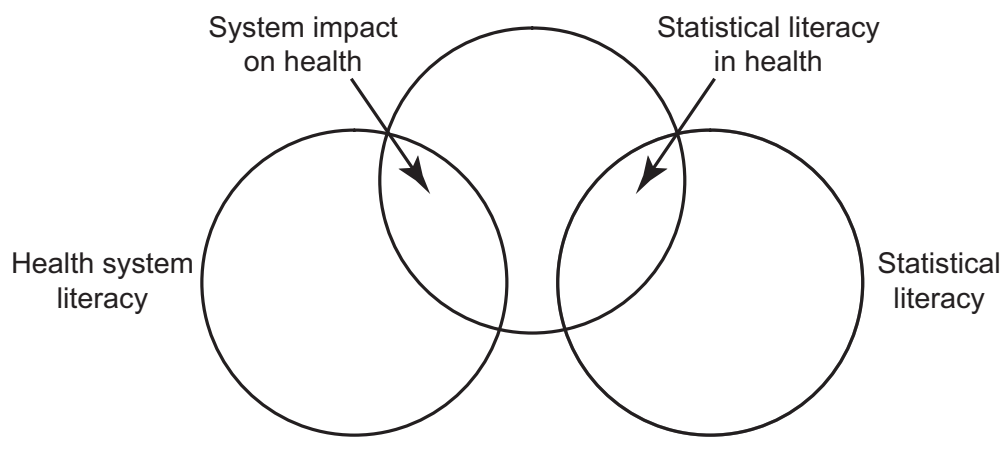

Figure 1.1 Three basic competencies for doctors and patients in the 21 st century. Health system literacy entails basic knowledge about the organization of a system and the incentives within it, such as the widespread practice of defensive medicine as a reaction to the threat of litigation. Health literacy entails basic knowledge about diseases, diagnostics, prevention and treatment, and ways to acquire reliable knowledge. Statistical literacy involves the ability to understand uncertain evidence, including concepts such as 5-year survival rates and false positives. The health care system inherited from the 20th century has done little to develop these basic competences in doctors and patients, promoting drugs, patents, and health technology instead. 


\section{Biased Funding}

The formation of misinformed doctors and patients begins with the funding of research. Given the increasing role of private industry, profitability has become a primary motive for funding and guides the selection of research topics. In 2008, an estimated US\$160 billion was spent on health research and development (R\&D) in the United States, and more than half originated from industrial sources; that is, pharmaceutical, biotechnology, and medical technology companies (see Nelson, this volume, for other countries). The rapid rise of the industry began with the election of Ronald Reagan in 1980, when Congress enacted a series of laws, including the Bayh-Dole Act, which enabled universities and small businesses to patent discoveries sponsored by the National Institutes of Health (NIH). Before 1980, taxpayer-financed discoveries belonged in the public domain and could be used by any company (Angell 2004). Today, discoveries made by taxpayer-funded research are no longer public; they can be patented and sold to industry, which in turn can charge large sums until the patent expires or competitors are allowed to introduce generic drugs. Before 1980, medical researchers worked largely independently of the companies that sponsored their work, but this is no longer the case. The Reagan years gave a tremendous boost to the "technology transfer" between universities and industry, where medical schools and their faculties entered into lucrative financial arrangements with drug companies. By funding research at universities and outside, industry is able to introduce bias in three ways: by determining the topics that are funded, the design of clinical trials, and the reporting of the results in journals.

The term "biased funding" refers to research funded because it is likely to be profitable, not because it is likely to be relevant for patients. Profitability and relevance can coincide, but often do not. The James Lind Alliance (www. lindalliance.org), for instance, identifies unanswered relevant questions from patients to ensure that those who fund health research are aware of what matters to patients. We illustrate biased funding by pinpointing three blind spots: patient safety, innovative drugs, and physicians' statistical literacy.

\section{Patient Safety}

Checklists provide a simple, inexpensive tool for improving safety. Introduced by the U.S. Air Force after the B-17 proved to be too much of an airplane for any one person to fly, checklists have become the safety backbone in commercial aviation. For instance, during the successful emergency landing of US Airways Flight 1549 in the Hudson River, the two pilots relied on the relevant checklists, including those for engine failure and evacuation (Gawande et al. 2009). Whereas customer safety is a priority in aviation, and all pilots are trained to use checklists, neither is the case in medicine. For instance, each year, central venous catheters cause an estimated 80,000 bloodstream infections and, 
as a result, up to 28,000 deaths in intensive care units (ICU) in U.S. hospitals. Total costs of these infections are estimated at US\$2.3 billion annually. To save lives, Peter Pronovost developed a simple checklist of five steps (including hand washing and cleaning the skin with chlorhexidine) for ICU doctors to follow before inserting an IV line to prevent the introduction of bacteria. The checklist reduced the infection rate to almost zero at some one hundred ICUs in hospitals in Michigan (Pronovost et al. 2006). One might think that funding would focus on such strong effects and that hospitals would rush to implement checklists. Yet most ICU physicians do not use them. Infection control has not been a priority of administrators, who focus on hospitals' profits rather than on patient safety. Nor is the hierarchical structure in hospitals fertile ground for checklists, which might require a nurse to remind a surgeon to follow the instructions. But a fundamental reason why so little funding has been made available to develop and implement checklists appears to be that they are cheap, and thus do not promise high-profit patents.

Patient safety is a major problem. The Institute of Medicine estimated that some 44,000 to 98,000 patients are killed every year in U.S. hospitals by documented, preventable medical errors (Kohn et al. 2000). In 2009, the WHO reported that nearly 1 in 10 patients are harmed while receiving care in wellfunded and technologically advanced hospitals (WHO 2009a). Little is known about non-hospital settings, where the majority of care is delivered. In 2008, the WHO Patient Safety initiated a grants program to provide seed funds for twenty to thirty small research projects on safety. Patient safety needs to become a major focus of funding.

\section{Me-too Drugs}

To gain approval by the U.S. Food and Drug Administration (FDA), a company needs only to show that its drug is better than a placebo, not that it is better than an already existing drug. The same is true in Germany and other European countries. As a result, there is little incentive for a company to fund innovative research for better drugs; all they need to do is to change a few molecules of an old, already approved one and produce a "me-too" drug. Research on me-too drugs has a smaller risk of failure than innovative research. Of the 78 drugs approved by the FDA in 2002, 71 were me-too drugs (Angell 2004:17). Research that results in drugs that are not better than already existing ones-only more expensive as long as the patent lasts - is not in the interest of the patient.

Research that is relevant for patients has a different goal: Is the new drug better or worse than the old one? Sometimes, such comparative effectiveness research is conducted. For instance, consider high blood pressure (hypertension), a condition for which about 25 million Americans are treated. A trial not sponsored by a drug company compared four drugs for treating hypertension: Norvasc $^{\circledR}$ (amlodipine besylate), the fifth best-selling drug in the world in 2002 sold by Pfizer; Cardura ${ }^{\circledR}$ (doxazosin), also from Pfizer; an ACE inhibitor sold 
by AstraZeneca as Zestril ${ }^{\circledR}$ (lisinopril) and by Merck as Prinivil ${ }^{\circledR}$; and a generic diuretic ("water pill") of a type that has been on the market for over fifty years. The study found that the old-time diuretic was just as effective in lowering blood pressure and better for preventing heart disease and stroke (ALLHAT Collaborative Research Group 2002). Last but not least, diuretics were priced at about US\$37 a year in 2002, while Norvasc ${ }^{\circledR}$ costs $\$ 715$. Comparative studies are, however, rare. Drug companies do not like head-to-head comparisons with older drugs and use their influence to make certain that the FDA or similar institutions do not request that research answers the comparative question relevant for the patient. The design of research is directly influenced when pharmaceutical companies require researchers to compare a new drug with a placebo rather than with an already existing drug (Angell 2004).

If comparative research is conducted, the drug of the supporting manufacturer is sometimes given at a higher dose than the comparator drugs. (This can make a new drug look good even if it might actually be worse than the older one; yet in the absence of proper studies, no one will know.) Consider Prilosec $^{\circledR}$ (omeprazole), a heartburn drug made by AstraZeneca which was once the top-selling drug in the world with US\$6 billion in annual sales. When the blockbuster was set to go off patent in 2001, the company faced competition from generic manufacturers who would sell Prilosec ${ }^{\circledR}$ at a much lower price. To avoid loss in sales, AstraZeneca patented a virtually identical drug, Nexium $^{\circledR}$, and spent a half billion dollars the same year on advertisements, discounts to managed care plans and hospitals, free samples to doctors, coupons in newspapers, and other ways of persuading consumers to switch from Prilosec ${ }^{\circledR}$ to Nexium ${ }^{\circledR}$. AstraZeneca conducted four comparative trials; in two of these, Nexium ${ }^{\circledR}$ came out marginally better than Prilosec ${ }^{\circledR}$. But the company had loaded the die by using different doses: $20 \mathrm{mg}$ of Priolosec ${ }^{\circledR}$ were compared with $40 \mathrm{mg}$ and $20 \mathrm{mg}$ of Nexium ${ }^{\circledR}$. Biased comparative research is not helpful for patients, who could simply double the dose of Priolosec ${ }^{\circledR}$ or buy a much cheaper generic.

Research on me-too drugs that does not conduct comparative studies with existing drugs is not in the interest of the patient. Ironically, the patient pays twice: as a taxpayer for the research supported by the NIH or other government organizations, and as a patient for the overpriced drugs sold by the pharmaceutical companies that acquired the patents without conducting innovative research.

\section{Physicians' Statistical Literacy in Health}

The general public believes that every physician understands medical evidence such as health statistics. Yet the few existing studies indicate that this is not the case, even in the physicians' own specialty. For instance, one of us (GG) trained about 1,000 German gynecologists in risk communication as part of their continuing education in 2006 and 2007. The majority of gynecologists 
falsely believed that among every 10 women with a positive screening mammogram, 8 or 9 actually have breast cancer, whereas the best estimate is only about 1 (Gigerenzer et al. 2007). These gynecologists' lack of statistical literacy causes unnecessary fear and panic in women with false positive results. More generally, studies indicate that most physicians confuse an increase in 5 -year survival rates in screening with a decrease in mortality (Wegwarth et al., submitted) and do not understand how to determine the positive predictive value of a test (Hoffrage and Gigerenzer 1998), and about a third of physicians overestimate benefits if expressed as relative risk reductions (Gigerenzer et al. 2007). Moreover, physicians often confuse concepts such as sensitivity and specificity, and do not know the scientific evidence for benefits and harms of standard tests and treatments (Gigerenzer 2002).

Funding has focused on new technologies and drugs, not on physicians' understanding of these technologies. Although we have developed framing methods to help doctors understand health statistics quickly (Gigerenzer et al. 2007), there is relatively little research on these and even less implementation. In this way, biased funding contributes to ever more technology and less health literacy.

\section{Manifesto for Action to Make Research More Relevant for Patients}

During the second half of the 20th century, a system of funding research was created whose primary goal does not appear to support medical research relevant for the patient. Because the causes are multiple and hard to change, a solution might focus on identifying what we call a "triggering factor," that is, a causal factor that takes care of multiple others like a domino effect. Here are three triggering factors for patient safety, me-too drugs, and doctors' statistical literacy.

1. Research funders, such as the NIH in the United States, the National Institute for Health Research (NIHR) in the United Kingdom, and the Deutsche Forschungsgemeinschaft in Germany, should invest in research on why professional practices that harm patients continue to exist, even when there are evidence-based interventions such as checklists to reduce these harms.

2. Regulatory agencies, such as the FDA in the United States, the Medicines and Healthcare Products Regulatory Agency (MHRA) in the United Kingdom, and research funders all over the world, should adopt the principles of comparative effectiveness research and make the approval of a new drug contingent on whether it is substantially more effective, safer, or has fewer side effects than those already in existence - not on whether it is better than a placebo. This single factor could not only stop the stream of me-too drugs, which wastes research money and resources, but also encourage innovative research to 
develop better products. The change in the U.S. system as evidenced by the support for comparative effectiveness research in major medical journals, such as $J A M A$, is a welcome sign of change.

3. Research funders should invest in research on the causes and the cure of statistical illiteracy in health care providers. A problem that is so widespread and with such direct detrimental consequences to patients' health can be classified as a pandemic, affecting more people than bird flu and SARS combined.

\section{Biased Reporting in Medical Journals}

To foster complete and transparent reporting of research, medical journals have ethical guidelines. These include CONSORT for randomized trials and MOOSE for systematic reviews. Similarly, the Declaration of Helsinki specifies that authors, editors, and publishers have an ethical obligation to report honestly. One would therefore assume that the top medical journals always report results in a transparent and complete manner; however, this is not the case (Nuovo et al. 2002).

\section{Transparent Reporting}

Every health statistic can be reported in a transparent or misleading way. For instance, absolute risks, mortality rates, and natural frequencies are transparent, whereas relative risks, 5-year survival rates, and conditional probabilities (e.g., sensitivities) tend to mislead physicians and patients alike. At issue is not one of lying, but rather the art of saying something correctly in a way that most listeners will understand incorrectly.

For instance, consider mismatched framing (Gigerenzer et al. 2007): The benefits of a test or treatment are featured in big numbers as relative risks while harms are displayed in small numbers as absolute risks. Assume that a treatment reduces the probability of getting disease A from 10 to 5 in 1,000, while it increases the risk of disease B from 5 to 10 in 1,000 . The journal article reports the benefit as a $50 \%$ risk reduction and the harm as an increase of 5 in 1,000 ; that is, $0.5 \%$. An analysis of the articles published in the British Medical Journal (BMJ), the Journal of the American Medical Association (JAMA), and The Lancet, 2004-2006, showed that mismatched framing was used in one out of every three articles (Sedrakyan and Shih 2007). We believe it is ethically imperative for editors to enforce transparent reporting: no mismatched framing, no relative risks without baseline risks, and always in absolute numbers. Absolute risks or numbers needed to treat may not look as impressive, but the goal of a medical journal must be to inform — not persuade. 


\section{Complete Reporting}

If results are not completely reported, it is impossible to judge whether a treatment is appropriate for a patient. Reporting can be biased in several ways. The first is to report just the favorable trials, not all trials. For instance, if two studies showed a positive effect of a treatment, but eight others showed negative results, it is essential that all are reported. However, complete reporting of all studies is neither enforced nor required in most countries. In the United States, the FDA requires a company to submit all trials that it has sponsored; it does not require that all studies be published. For example, the agency typically requires evidence that the drug worked better than a placebo in two clinical trials, even if it did not in the other trials (Angell 2004). As a result, treatments tend to look better than they are.

A second bias is introduced when only the favorable part of the data is reported, but not all data. For instance, consider the clinical trial of the arthritis drug Celebre ${ }^{\circledR}$, sponsored by Pharmacia (since acquired by Pfizer). Only after publication in JAMA did the outraged editors learn that the results were based on only the first six months of a year-long trial. An analysis of the entire year showed no advantage of Celebrex ${ }^{\circledR}$ (Angell 2004).

A third bias is introduced when researchers "cherry-pick" and report only those variables or subgroups that showed favorable results. Companies' attempts to prevent researchers from publishing their results when they are not favorable are one of the reasons why cherry-picking occurs (e.g., Rennie 1997). Finally, complete reporting is violated and biases are introduced when high-impact medical journals carry advertisements that make promotional statements, but the statements are not supported by the evidence in the bibliographic references given (Villanueva et al. 2003).

Why do editors of major journals not strictly enforce transparent and complete reporting? One answer is conflicting interests, just as in funding of research. It may not be accidental that one-third of the trials published in $B M J$ and between two-thirds and three-quarters published in the major North American journals were funded by the pharmaceutical industry (Egger et al. 2001). Studies funded by the pharmaceutical industry more often report results favorable for the sponsoring company than do studies funded by other sources (e.g., Lexchin et al. 2003). It is in the very interest of companies to frame the results in a way that impresses doctors. Richard Smith (2005), former editor of $B M J$, explains that a publisher depends not only on the advertisements paid by the industry, but even more on the tens of thousands of reprints that the pharmaceutical industry often purchases to distribute to physicians. "Journals have devolved into information laundering operations for the pharmaceutical industry," wrote Richard Horton (2004:9), editor of The Lancet. Biased reporting does not begin in press releases or the media, as it is sometimes assumed. It already exists in the top international medical journals. In the 2003 $B M J$ Christmas issue, David Sackett and Andrew Oxman published a satirical 
article on distorted reporting of evidence, offering their services on "how to achieve positive results without actually lying to overcome the truth" (Sackett and Oxman 2003:1442).

\section{Manifesto for Action to Stop Biased Reporting in Medical Journals}

1. Research funders should (a) structure research application forms so that researchers have to submit their application following the guidelines for their research method, such as CONSORT for randomized controlled trials; (b) ensure that a systematic review of the evidence has been done before new data are collected; and (c) require a research protocol that specifies all research hypotheses and how they are being tested in advance to guarantee completeness of reporting.

2. Journal editors and publishers should sign up to the principles and practices agreed upon by the Sixth International Congress on Peer Review and Biomedical Publication, using the tools made openly available through the EQUATOR Network, and strictly enforce these. These principles need to be extended to include transparent reporting of health statistics. Editors should clearly announce that evidence framed in relative risks (without base lines), 5-year survival rates for screening, mismatched framing, and other nontransparent formats will no longer be published (Gigerenzer et al. 2007).

3. Institutions that subscribe to medical journals should give journal publishers two years to implement the previous action and, if publishers do not comply, cancel their subscriptions.

\section{Biased Reporting in Health Pamphlets and Web Sites}

In a recent poll of 10,228 people from nine European countries, $21 \%$ responded that they sometimes or frequently consult leaflets and pamphlets from health organizations, with the highest number (41\%) coming from Germany (Gigerenzer et al. 2009). Yet the amount of biased reporting that stems from this material - typically omissions of harms and overstatement of benefits - is staggering. For instance, analyses of 150 pamphlets (including invitations) on mammography screening showed that benefits are mostly reported in relative risks (108 cases) but rarely in absolute risks (26 cases) or number needed to treat (11 cases), while the harms from overdiagnosis and unnecessary treatment were only mentioned in 37 cases (Gigerenzer et al. 2007). This combination of nontransparency and incomplete reporting hinders informed decision making. Many pamphlets appear to be designed to increase participation rates rather than inform the public. In fact, in Germany, where consulting rates of medical pamphlets were the highest, there is a negative correlation between frequency of consulting pamphlets and understanding the benefit of mammography 
screening (Gigerenzer et al. 2009). Moreover, 98\% of German women overestimate the cancer-specific mortality reduction of mammography screening or do not know, consistent with a high reliance of information from pamphlets.

Mismatched framing spreads from medical journals to health pamphlets, web sites, and patient information. For instance, the National Cancer Institute's Risk Disk is intended to help women make informed decisions about whether to use tamoxifen for the primary prevention of breast cancer (Schwartz et al. 1999 b). The benefit is framed as a relative risk reduction: "Women [taking tamoxifen] had about $49 \%$ fewer diagnoses of invasive breast cancer." The harm of increased uterine cancer, in contrast, is framed as an absolute risk increase: "The annual rate of uterine cancer in the tamoxifen arm was 30 per 10,000 compared to 8 per 10,000 in the placebo arm" (NCI 1998). Transparent reporting would express both as absolute risks. Analyzing the study data reveals that in absolute terms, the $49 \%$ refers to a reduction from 33 to 17 in 1,000; that is, 16 in 1,000. Moreover, the Breast Cancer Prevention Study Fact Sheet (NCI 2005) reports only the $49 \%$ statistic and no numbers at all for the increased risk of uterine cancer.

Analyses of web sites showed similar degrees of biased reporting, specifically web sites from advocacy groups and governmental organizations. Those from consumer organizations, however, contained more balanced reporting (Jorgensen and Gøtzsche 2004).

For a busy doctor with limited time to keep abreast of medical research, leaflets from the pharmaceutical industry are a major source of information. Pharmaceutical companies dispatch thousands of well-dressed representatives with leaflets and samples in their hands to persuade doctors to prescribe their drugs. A leaflet typically summarizes the results of a published study in a convenient form. A comparison of 175 leaflets with the original studies showed surprisingly that the summaries could be verified in only $8 \%$ of the cases. In the remaining $92 \%$, key results were systematically distorted, important details omitted, or the original study could not be found or was not mentioned (Kaiser et al. 2004). In general, leaflets exaggerated baseline risks and benefits, enlarged the length of time in which medication could safely be taken, or did not reveal severe side effects of medication pointed out in the original publications.

\section{Manifesto for Action to Stop Biased Reporting in Health Pamphlets and Web Sites}

1. Every hospital and health care provider should nominate a member of their senior management team to take responsibility for ensuring that all patient information is (a) unbiased from an evidence-based standard and (b) transparent for the patient. Transparent reporting includes the use of absolute risks as opposed to relative risks (without base lines), mortality rates for screening (as opposed to 5-year survival rates), natural frequencies (as opposed to conditional probabilities), and techniques 
to present these clearly (e.g., diagrams, as in Gigerenzer 2002:45). Health care payers, such as governments and health insurance companies, should ensure that providers implement this action. Doing so will both reduce waste of taxpayers' money and improve patient well-being.

2. National ministries of health that determine strategy and policy should make an explicit commitment to quality of patient information, as announced by the U.K. Prime Minister David Cameron when the new policy for the National Health Service (NHS) was introduced (Dept. of Health 2010:13): "The Government intends to bring about an NHS information revolution, to correct the imbalance in who knows what. Our aim is to give people access to comprehensive, trustworthy, and easy to understand information." Health care regulators, such as the state governments in Germany and the Care Quality Commission in England, should add monitoring the quality of information given to patients to their range of services.

3. Members of institutions that support the democratic ideal of educated patients should make biased information a public issue. The lever is the reputation of organizations that produce health pamphlets, such as patient organizations and charities. For instance, in a number of public lectures, one of us (GG) showed how the widespread misinformation about cancer screening among doctors and patients could be traced back to biased reporting in the pamphlets of the Deutsche Krebshilfe and offered to help rewrite the pamphlets in a complete and transparent way. The institution accepted, and since late 2009, an entirely new set of short brochures was published, in which all misleading relative risk reductions and 5-year survival rates were replaced by transparent absolute numbers and the evidence for harms is no longer omitted.

\section{Biased Reporting in the Media}

Europeans consult the general media (television, radio, popular magazines, and daily newspapers) for health information more often than specialized medical sources such as pamphlets and leaflets (Gigerenzer et al. 2009). Yet journalism schools tend to teach everything except understanding evidence, even though health is the leading science topic in U.S. and European media. A survey of health reporters in five Midwestern states found that $80 \%{ }^{1}$ had no training in covering health news or interpreting health statistics (Voss 2002). Combined with the fierce competition for journal space and the attention of readers, this lack of training results in waves of unnecessary fears and hopes. To illustrate, consider one of the recurring contraceptive pill scares in the United Kingdom.

1 Surveys were sent to 165 reporters from 122 newspapers in 5 Midwestern states to assess the association of training, newspaper size, and experience with reporter's self-perceived reporting ability (Voss 2002). 
In 1995, the U.K. Committee on Safety of Medicines issued a warning that third-generation oral contraceptive pills increased the risk of potentially lifethreatening blood clots in the legs or lungs twofold; that is, by $100 \%$. The news caused great anxiety, and many women stopped taking the pill, which led to unwanted pregnancies and abortions - some 13,000 additional abortions in the following year in England and Wales, and an extra £4-6 million in costs for the National Health Service. Yet how big was the $100 \%$ risk? The studies revealed that out for every 7,000 women who took the earlier, second-generation pills, 1 had a thrombosis, and this number increased to 2 among women who took third-generation pills. The difference between a relative risk increase $(100 \%)$ and an absolute risk increase (1 in 7,000) was - and still is - not explained to the general public. The losers were the women, particularly adolescent girls, the taxpayers, and the pharmaceutical industry. The only winners were the journalists who got their story on the front pages.

Systematic analyses of media reports reveal three major biases: the omission of numbers, the use of nontransparent numbers (as in the pill scare), and the lack of cautionary notes. These biases do not always originate in the mind of journalists; they may already exist in journal articles. Moreover, press releases suffer from many of the same problems (Woloshin and Schwartz 2002). They often fail to quantify the main effect ( $35 \%$ of 127 press releases), present relative risks without base rates (45\%), and make no note on study limitations (77\%).

After doctors, pharmacists, and friends, television is the most frequented source of health information in European countries. In a recent survey $(10,228$ participants), $43 \%$ stated that they relied on TV reports sometimes or frequently. Yet when it came to understanding the benefits of breast and prostate cancer screening, those Europeans who relied more often on TV, radio, magazines or daily newspapers were not better informed (Gigerenzer et al. 2009). Although a few informative TV programs do exist, our personal experience with producers and talk show hosts is that most prefer entertaining stories, in particular about celebrities, and poignant pictures to the task of informing the public.

A few newspapers have begun to promote correct and transparent reporting in place of sensationalism and confusion. In the United States, journalists are taught at MIT's Medical Evidence Boot Camp, the Medicine in the Media program sponsored by NIH and the Dartmouth Institute for Health Policy and Clinical Practice's Center for Medicine and the Media.

\section{Manifesto for Action to Stop Biased Reporting in the Media}

1. Departments of journalism at universities should teach epidemiological principles and transparent risk communication. No journalist should be left behind.

2. Governments and public health professionals at national, regional, and local levels should accept that the population they serve needs clean and clear knowledge as much as it needs clean and clear water. They 
should use their existing channels for health communication not only for transmitting unbiased evidence, but also to counter misleading and sensational media stories quickly and authoritatively. Examples of this approach can be found on the web sites of Behind The Headlines Service, which is part of NHS Choices, and Media Watch.

3. Health professionals and professional bodies should support the work of freelance writers who produce resources such as the blog sites Bad Science and Selling Sickness when they are attacked or sued by industry or other pressure groups.

\section{Conflicts of Interest}

Germany spends about 240 billion Euros on health care annually, about $11 \%$ of its GDP, whereas the United States spends 17\%, about double the expenditure in the United Kingdom. In 2002, for instance, the ten drug companies in the Fortune 500 made more profit (US\$35.9 billion) than all the other 490 businesses together (US\$33.7 billion; Angell 2004). Conflicts of interest are to be expected when so much money is at stake.

A conflict of interest occurs when a doctor, hospital, or industry cannot simultaneously improve care for patients and its own revenues, but has to choose. Such conflicts arise elsewhere in business and politics, but with a different outcome. When Toyota built better cars for less money, for example, it won new customers. Rivals such as Honda either matched its quality and success, or like General Motors, lost their market share. This basic economic principle — better quality, higher profits - holds in most markets, but health care is a big exception. If a hospital provides better quality by reducing unnecessary and potentially harmful treatments, it reduces costs, but it may also reduce its revenues even more. Patients, in particular in the United States, show little inclination to buy better and less expensive care, although they would buy better and less expensive cars. When one of us (GG) attended an internal talk at a leading pharmaceutical company, the speaker, a health economist, said jokingly, "Assume we discovered a drug that is both better and cheaper than what we have. Is there anyone who believes that it would get on the market?" The audience exploded into laughter. Yet the demanding consumers who nearly brought the U.S. automobile industry to its knees could do the same to the medical industry.

Why is Western health care not like the Japanese car industry? One factor is the incentive structure that can conflict with the goal of providing the best service to the patient. If doctors are paid for each extra test and treatment, as in fee-for-service payment systems, they have conflicting interests. Services for which physicians get little pay from health insurances (e.g., taking time to inform patients or paying home visits) are discouraged, whereas those that increase the flow of income (e.g., such as surgery and imagery) are encouraged. 
The doctor achieves higher earnings by ordering unnecessary tests and treatments, which may harm rather than help the patient. If physicians were paid a salary rather than for each service, as at the Mayo Clinic in Minnesota, such conflicts of interest would be resolved and patients could get better quality care for less money. Some hospitals have followed the Mayo model and investigated their own overuse of tests. For instance, hospital leaders from Cedar Rapids, Iowa, examined the overuse of CT scans and found that in just one year 52,000 scans were done in a community of 300,000 people. A large proportion was unnecessary and potentially harmful, as the radiation exposure of a CT scan can be about 1,000 times as large as a chest X-ray (Gawande et al. 2009).

A second source of conflict for doctors is (pseudo-)research contracts offered by industry. After a new drug has been approved, a company offers doctors a certain amount of money for each patient they put on the new drug. The research part consists of a summary form that is typically short and simple. Such studies can be sometimes useful for learning more about a new drug, but they create a conflict between monetary incentives and the best health care for the patient. In 2008, German doctors participated in such studies in 85,000 cases (out of about 150,000 doctors in private medical practice), and earned between 10-1,000 Euros per patient, often without informing patients why they were put on the new drug. The conflict is this: Doctors who refuse to be paid for putting their patients on the new drug earn less money.

Financial incentives are not the only source of conflicting interests for doctors. For instance, the formal requirement of completing a certain number of surgeries to qualify as a specialist can cause a conflict between persuading a patient to have a surgery and providing the best care for the patient.

Hospitals are subject to conflicts of interest as well. These appear to be a cause of the striking phenomenon of unwarranted practice variability, as recorded in the Dartmouth Atlas of Health Care. Since the 1970s, Jack Wennberg and his collaborators have systematically documented large and unwarranted variability in practice in North America and Europe. For instance, $8 \%$ of the children in one referral region in Vermont had their tonsils removed while in another area $70 \%$ underwent tonsillectomies. In Maine, the proportion of women who have had a hysterectomy by the age of 70 varies between communities from less than $20 \%$ to more than $70 \%$. In Iowa, the proportion of men who have undergone prostate surgery by age 85 ranges from $15 \%$ to more than $60 \%$. Wild variability in surgery is not limited to the United States. In Magdeburg, Germany, similar "small area variations" were reported for elective surgical procedures (back and hip) (Swart et al. 2000). In Hessen, the rate of breast-conserving surgery conducted under similar conditions varied widely (from $0-100 \%$ ) in 78 clinics, suggesting that treatments are based neither on the best science nor on women's preferences (Geraedts 2006).

More is not better. In the United States, regions with high utilization and expensive care show slightly worse mortality outcomes, lower perceived access, and less patient satisfaction (Fisher et al. 2003a, b). Among the factors 
that drive this variability are the number of unoccupied hospital beds available, the number of imaging techniques, and other available supply in a hospital, as well as the number of physicians in a region. Once an expensive capacity has been built, a conflict arises between using it for the best profit of the hospital and providing the best health care for the patient.

When Wennberg and his colleagues first published their results, the most surprising reaction was that no public outcry ensued. When, on the occasion of the U.S. health care reform plan in 2009, the physician-writer Atul Gawande made some of these results accessible to a wider audience in the New Yorker, they were met once again largely with silence. We need better doctors and better patients: people who react to practice variation rather than allow themselves to be acted upon.

\section{Manifesto for Action to Reduce Interests Conflicting with Best Care}

1. Those who determine physician reimbursement should move away from fee-for-service payments to good salaries. There is evidence that fees-for-service encourage unnecessary tests and treatments, including surgery and imaging, leading to more harm done to patients and a waste of taxpayers' money. Salaries encourage better quality, better risk communication, and free time for doctors to take care of their patients' needs, including time to talk without decreasing doctors' income.

2. Those who pay for health care, such as governments and insurance companies, should discontinue payment incentives that increase the rate of interventions unless there is very strong evidence that an increased rate of interventions does more good than harm. For example, it is appropriate to use incentives to increase immunizations to nearly $100 \%$, whereas incentive schemes that would increase the rate of elective surgical operations on the knee may do more harm than good.

3. Medical organizations responsible for continuing medical education should stop using industry funding to sponsor educational programs.

\section{Defensive Medicine}

One might assume that doctors who succeed in circumventing biased information and conflicts of interest would be free to treat their patients according to the best evidence. Yet this is not so. Tort law in many countries and jurisdictions not only discourages but actively penalizes physicians who practice evidence-based medicine (Monahan 2007). For instance, Daniel Merenstein (2004), a young family physician in Virginia, was sued in 2003 because he had not automatically ordered a PSA test for a patient, but instead followed the recommendations of leading medical organizations and informed the patient about its pros and cons. The patient later developed an incurable form of 
prostate cancer. The plaintiff's attorney claimed that the PSA tests are standard in the Commonwealth of Virginia and that physicians routinely order the test without informing their patients. The jury exonerated Merenstein, but his residency was found liable for US\$1 million. After this experience, Merenstein felt he had no choice but to practice defensive medicine, even at the risk of causing unnecessary harm: "I order more tests now, am more nervous around patients; I am not the doctor I should be" (Gigerenzer 2007:161).

The term "defensive medicine" refers to the practice of recommending a diagnostic test or treatment that is not the best option for the patient, but one that protects the physician against the patient as a potential plaintiff. Defensive medicine is a reaction to the raising costs of malpractice insurance premiums and patients' bias to sue for missed or delayed diagnosis or treatment. The saying goes: "No one is ever sued for overtreatment." Ninety-three percent of 824 surgeons, obstetricians, and other U.S. specialists at high risk of litigation reported practicing defensive medicine, such as ordering unnecessary CTs, biopsies, and MRIs, and prescribing more antibiotics than medically indicated (Studdert et al. 2005). Being sued costs time and money for the doctor, including the time away from patient care that litigation entails as well as possible damage in reputation. An analysis of a random sample of 1452 closed malpractice claims from five U.S. liability insurers showed that the average time between injury and resolution was five years. Indemnity costs were US\$376 million, defense administration costs $\$ 73$ million, resulting in total costs of $\$ 449$ million (Studdert et al. 2006). The system's overhead costs were exorbitant: $35 \%$ of the indemnity payments went to the plaintiffs' attorneys, and together with defense costs, the total costs of litigation amounted to $54 \%$ of the compensation paid to plaintiffs.

U.S. physicians are at highest risk of being sued, and overtreatment is common. In 2006, Americans underwent 60 million surgical procedures, 1 for every 5 Americans (Gawande et al. 2009). No other country operates on their citizens so frequently. Nobody knows whether Americans are better off because of this, but it seems unlikely; we also do not know how many of these surgeries qualify as defensive treatments. We know, however, that every year, hundreds of thousands of Americans die from surgical complications - more than from car crashes and AIDS combined.

In Switzerland, where litigation is less common, $41 \%$ of general practitioners and $43 \%$ of internists reported that they sometimes or often recommend PSA tests for legal reasons (Steurer et al. 2009). The practice of defensive medicine also expresses itself in discrepancies between what treatments doctors recommend to patients and what they recommend to their own families. In Switzerland, for instance, the rate of hysterectomy in the general population is $16 \%$, whereas among doctors' wives and female doctors it is only $10 \%$ (Domenighetti et al. 1993).

One triggering factor that could reduce the practice of defensive medicine is to replace the custom-based legal standard of care by evidence-based liability. 
As the case of Merenstein illustrates, even if doctors deliver best practice to a patient, their clinics can be successfully sued, because medical custom ("what most other doctors do"), not scientific evidence, defines the legal standard of care. Malpractice suits are often seen as a mechanism to improve the quality of care, but with custom-based liability, they actually impede the translation of evidence into practice, harming patients and decreasing the quality of care. In the United States, state courts are "gradually, quietly, and relentlessly" abandoning the custom-based standard of care (Peters 2002), yet a clear commitment to scientific evidence is needed. One factor that impedes change is that lawyers and judges, similar to doctors, receive little if any training in understanding evidence. One of us (GG) trained U.S. federal judges in statistical literacy in 2004-2005, but these courses, carried out under the continuing education program organized by George Mason School of Law, appear to have been the only ones ever conducted. Out of some 175 accredited law schools in the United States, only one requires a basic course in statistics or research methods (Faigman 1999). As a consequence, judges, jurors, and attorneys are continuously misled by nontransparent statistics presented in court (Gigerenzer 2002).

\section{Manifesto for Action to Protect Patients from Defensive Medicine}

1. Ministries of health should identify features of the legal system that increase the likelihood of being sued for not performing a clinical intervention that has no evidence of benefit. Unlike the European legal systems, the U.S. tort law encourages malpractice suits, which has the unintended consequence of decreasing quality of care by forcing physicians to practice defensive medicine. The resulting exorbitant fees for malpractice insurance and lawyers add to the costs of health care.

2. Those who pay for health care (governments and insurance companies) should make explicit to clinicians and patients the care pathways that give the best balance of benefit and harm with the resources available. They should also state explicitly which interventions (e.g., PSA screening tests, imaging) are more likely to do harm than good, and should therefore not be conducted. Evidence-based shared decision-making tools (e.g., those developed by the Foundation for Informed Medical Decision Making) should be used for patients' decisions when either options have dramatically different outcomes or when patient values about the balance of benefits and risks are particularly important (e.g., elective surgery). To ensure that all options and their consequences have been clearly transmitted, health care providers should start recording patient knowledge before and after the consultation. DartmouthHitchcock Medical Center is already doing this for women's decisions about breast cancer treatment.

3. All agencies and professionals who are in the position to help improve health system literacy should make it clear to the public and the media 
that concern about overuse of medical care has primarily to do with the resulting harms and that this would be a matter of equal concern even if finances were unlimited. More is not always better.

\section{Doctors' Statistical Illiteracy}

The last element in the chain that leads to misinformed patients is probably the least known. It is commonly assumed that only patients have problems with health statistics, not their physicians. Most legal and psychological articles on patient-doctor communication assume that the problem lies in the patient's mind. Doctors may be said to not listen carefully to their patients' complaints, consult with them only five minutes on average, or withhold information. However, rarely is it considered that doctors themselves might not understand medical evidence (e.g., Berwick et al. 1981; Rao 2008). Yet most doctors that have been studied do not understand health statistics and thus cannot evaluate the evidence for or against a treatment, or critically judge a report in a medical journal (Gigerenzer et al. 2007). Lack of statistical literacy in health makes doctors dependent on the biased information contained in leaflets distributed by pharmaceutical companies (see above) or the continuing education organized by the industry. In the United States, there is 1 drug representative or detailer, as they are known, for every 5 or 6 doctors. Every week the average doctor is visited by several, who provide information, free samples, gifts such as golf balls or tickets to sporting events, and sometimes a free lunch for doctors and their staff (Angell 2004).

Consider Rudi Giuliani's statement mentioned at onset: that the 5-year survival rate for prostate cancer is $82 \%$ in the United States compared to only $44 \%$ in the United Kingdom under socialized medicine. Any physician should know that these figures tell us nothing about whether screening saves lives, because differences in 5-year survival rates do not correlate with differences in mortality rates (Welch et al. 2000). Yet would physicians see through Giuliani's misleading claim? To test this, Wegwarth et al. (submitted) gave 65 physicians practicing internal medicine the actual changes in 5-year survival rates from the Surveillance, Epidemiology and End Result (SEER) program for prostate cancer, which showed differences similar to those reported by Giuliani. Seeing the 5-year survival rates, $78 \%$ judged the screening as effective. When the same SEER data was given to the same physicians in terms of mortality rates (as mentioned before, the mortality rates are about the same), only 5\% judged the screening to be effective. Only 2 out of 65 physicians understood the leadtime bias, and not a single one understood the overdiagnosis bias.

Five-year survival rates are not the only kind of health statistics that confuse doctors. Conditional probabilities such as sensitivities and specificities provide another challenge. For instance, Gigerenzer et al. (2007) provided 160 German gynecologists with the relevant health statistics needed for calculating 
the chances that a woman with a positive screening mammogram actually has breast cancer: a prevalence of $1 \%$, a sensitivity of $90 \%$, and a false positive rate of $9 \%$. The physicians were asked: What would you tell a woman who tested positive that her chances were of having breast cancer? The best answer is that about 1 out of 10 women who test positive actually have cancer; the others are false positives. Yet $60 \%$ of the gynecologists believed that 8 or 9 out of these 10 women actually have cancer, and $18 \%$ that the chances are 1 in 100 . Similar lack of understanding among physicians has been reported in the evaluation of positive HIV tests (Gigerenzer et al. 1998), in diabetes prevention studies (Mühlhauser et al. 2006), and other medical tests and treatments (Eddy 1982; Casscells et al. 1978; Ghosh and Ghosh 2005; Hoffrage et al. 2000; Young et al. 2002).

The inability of so many physicians to understand evidence in their own specialty is a disturbing fact. But medical schools and continuing education programs do not seem to acknowledge this collective statistical illiteracy as a fundamental problem of health care. Framing techniques have been developed to enable physicians to understand health statistics by representing the numbers in a transparent form (Gigerenzer 2002; Wegwarth and Gigerenzer, this volume). For instance, consider mammography screening again. It is easy to teach physicians to translate conditional probability information into natural frequencies: Think of 1,000 women. Ten are expected to have breast cancer, and of these, 9 test positive. Of the 990 women without cancer, about 89 nevertheless test positive. Now, almost all (87\%) gynecologists understood that 9 +89 will test positive, and only 9 of these actually have breast cancer, which amounts to roughly 1 out of 10 (Gigerenzer et al. 2007). This and other mental techniques can be efficiently taught in a few hours and - most important - unlike standard statistical training, the training effects do not fade away after a few weeks (Sedlmeier and Gigerenzer 2001). Some medical schools are presently adopting these techniques, but most still produce physicians who lack the ability to understand evidence. Without statistical literacy in health, informed medical decision making will remain an illusion.

\section{Manifesto for Action to Protect Patients from Statistically Illiterate Doctors}

1. Medical schools should ensure that students are taught transparent risk communication in addition to evidence-based skills. Evidence is necessary but not sufficient, given that doctors and patients alike are misled by nontransparent health statistics. For instance, the Charité in Berlin is currently introducing not only evidence-based medicine but also transparent risk communication for all medical students. The transparency program is outlined in Gigerenzer (2002) and Gigerenzer et al. (2007). 
2. Organizations responsible for continuing medical education and recertification programs should ensure that practicing doctors receive the same education in transparent risk communication as medical students.

3. Patients should have the courage to ask questions about the range of options, their quantitative benefits and harms, and insist on transparent answers from their doctors, just as if they were speaking to a school teacher about their child's progress. Patients can be resourceful, provided they are given the resources in the first place (Gray 2002). This will not only benefit patients but will also lead to a change in clinician behavior and reduce the risk of litigation for the institution. In this century of the patient, patients have responsibilities as well as rights.

\section{Creating the Century of the Patient}

The professionalization of modern medicine began in the 19th century. In most developed countries, people's health improved from a combination of clean water, better hygiene, and healthier and sufficient amounts of food. It also involved abandoning harmful procedures that had been popular for centuries, such as the extensive bleeding of patients to get rid of "bad" blood. This can be considered the first health care revolution.

The second half of the 20th century witnessed enormous scientific advances that gave us miracles such as the artificial hip and a cure for childhood leukemia, combined with the immense investment of resources in service expansion, professional education, and management. This second health care revolution created powerful systems of health care management. The 20 th century became the century of the doctor, the clinics, and the medical industry. Knowledgeable patients were not the primary goal of the second revolution, as illustrated by the pill scares in the United Kingdom and the striking misinformation of the general public in Europe and the United States about the pros and cons of cancer screening (Gigerenzer et al. 2009). Despite great advancements, the 20th century left us with uninformed doctors and patients, unwarranted practice variation that turns geography into destiny, waste of resources, and safety problems. Most countries can no longer afford such a wasteful system, and the recent financial crises provide a unique opportunity for change.

A third health care revolution is now needed. Whereas the first revolution brought clean water, the third should bring clean information. It should turn the 21 st century into the century of the patient - a genuinely democratic ideal. Citizens have the right to know the basic facts and a responsibility to base their health care decisions on the best available evidence. Our vision of a healthy health care system is that of a democracy where knowledge is distributed across all levels of society. It is not a new idea and has been expressed at various times in the past. Making good use of dispersed knowledge was essential for the first known successful democracy in Athens (Ober 2008). The costs of participatory 
political practices in Athens were more than matched by superior returns in social cooperation. This democratic ideal was also expressed by the second president of the United States, John Adams (2000/1765): "The preservation of the means of knowledge among the lowest ranks is of more importance to the public than all the property of all the rich men in the country." As the economist Friedrich Hayek (1945) has argued, liberty and democracy demand that a general knowledge be dispersed among the people. When it comes to health, the 20th century failed to promote educated citizens in modern democracies. Even worse, the current system itself causes, supports, and profits from the uninformed patient.

To achieve this third revolution, major efforts on many levels will be needed to reach its goals (Table 1.2). A critical mass of informed patients will not resolve all problems of health care, but they will constitute the major triggering factor for better care. Informed patients will ask questions that require doctors to become better informed and provide better care. They will be able to see through deception and attempts to create undue expectations and fears. The century of the patient requires the funding of research that is relevant for patients rather than for patents. It entails the enforcement of ethical guidelines about complete and transparent reporting in journals, brochures, and the media, and demands a legal system to protect patients and doctors alike against defensive medicine. Finally, it obliges medical schools to teach statistical literacy in health and transparent risk communication.

The century of the patient will involve more ways to transform the patient from a problem to a solution. For example, to improve the care of epilepsy, an excellent way would be to bring together patients, their parents, caretakers, and teachers with neurologists and other clinicians to develop solutions that reflect the practical and theoretical knowledge of all involved. This can lead to hypotheses about treatments that can be investigated in systematic research. The century of the patient will also involve a change in the doctor-patient relation, from frightened and ignorant patients who blindly trust their doctors toward shared decision making. Shared decision making has been promoted as an alternative to paternalism for some time, but given defensive decision

Table 1.2 Goals of the century of the patient.

\begin{tabular}{ll}
\hline & Funding of research relevant for patients \\
+ & Transparent and complete reporting in medical journals \\
+ & Transparent and complete reporting in health pamphlets \\
+ & Transparent and complete reporting in the media \\
+ & Incentive structures that minimize conflicts of interest \\
+ & Best practice instead of defensive medicine \\
+ & Doctors who understand health statistics \\
\hline$=$ & Informed patients \\
\hline
\end{tabular}


making and statistical illiteracy in health, informed shared decision making has rarely been possible.

Calls for better health care have been typically countered by claims that this demand implies one of two alternatives, which nobody really wants: raising taxes or rationing care. The problem, however, is not lack of money, and the cure is not more money. At issue is a better health system. The century of the patient is the third alternative: better doctors, better patients, and better care for less money. 